PULMONARY HYPERTENSION

\title{
Splenectomy and chronic thromboembolic pulmonary hypertension
}

\author{
X Jaïs, V loos, C Jardim, O Sitbon, F Parent, A Hamid, E Fadel, P Dartevelle, \\ G Simonneau, M Humbert
}

See end of article for authors' affiliations

Thorax 2005;60:1031-1034. doi: 10.1136/thx.2004.038083

....................

Correspondence to:

Dr X Jaïs, Centre des

Maladies Vasculaires

Pulmonaires, Service de

Pneumologie et

Réanimation Respiratoire,

Hôpital Antoine Béclère,

157 rue de la Porte-de-

Trivaux, 92140

Clamart, France; xavier.

jais@abc.ap-hop-paris.fr

Received

26 November 2004

Accepted 12 July 2005

Published Online First 5

August 2005
Background: An increased prevalence of splenectomy has been reported in patients with idiopathic pulmonary arterial hypertension. Examination of small pulmonary arteries from these subjects has revealed multiple thrombotic lesions, suggesting that thrombosis may contribute to this condition. Based on these findings, we hypothesised that splenectomy could be a risk factor for chronic thromboembolic pulmonary hypertension (CTEPH), a condition defined by the absence of thrombus resolution after acute pulmonary embolism that causes sustained obstruction of the pulmonary arteries and subsequent pulmonary hypertension.

Methods: The medical history, clinical characteristics, thrombotic risk factors and haemodynamics of 257 patients referred for CTEPH between 1989 and 1999 were reviewed. In a case-control study the prevalence of splenectomy in patients with CTEPH was compared with that of patients evaluated during the same period for idiopathic pulmonary hypertension $(n=276$ ) or for lung transplantation in other chronic pulmonary conditions $(n=180)$.

Results: In patients with CTEPH, $8.6 \%(95 \% \mathrm{Cl} 5.2$ to 12.0$)$ had a history of splenectomy compared with $2.5 \%(95 \% \mathrm{Cl} 0.7$ to 4.4$)$ and $0.56 \%(95 \% \mathrm{Cl} 0$ to 1.6$)$ in cases of idiopathic pulmonary arterial hypertension and other chronic pulmonary conditions, respectively $(p<0.01)$.

Conclusion: Splenectomy may be a risk factor for chronic thromboembolic pulmonary hypertension.
C hronic thromboembolic pulmonary disease is a cause of pulmonary hypertension. ${ }^{1-8}$ The condition is defined by the absence of thrombus resolution after one or more episodes of acute pulmonary embolic event that causes sustained obstruction of the pulmonary arteries and subsequent pulmonary hypertension. The extent of vascular obstruction is a major determinant of chronic thromboembolic pulmonary hypertension (CTEPH). However, in many patients, disease progression involves pulmonary vascular remodelling and the development of a specific pulmonary arteriopathy in the non-obstructed pulmonary vessels. Histological findings in small pulmonary arteries of patients with CTEPH are very close to that of idiopathic pulmonary arterial hypertension, including intimal fibrosis associated with organised thrombi and recanalisation, medial hypertrophy, as well as plexiform lesions. ${ }^{9}$ Recent studies indicate that anticardiolipin antibodies and/or a lupus anticoagulant are risk factors for CTEPH. ${ }^{10}{ }^{11}$

Pulmonary arterial hypertension may be either idiopathic or complicate the course of other conditions including connective tissue diseases, congenital systemic to pulmonary shunts, human immunodeficiency virus infection, portal hypertension, and appetite suppressant exposure. An increased prevalence of splenectomy has been reported in patients with so-called idiopathic pulmonary arterial hypertension, suggesting a link between splenectomy and the occurrence of this rare pulmonary vascular condition. ${ }^{12}$ Interestingly, examination of lung tissue of splenectomised patients who had undergone lung transplantation revealed multiple thrombotic lesions, supporting the hypothesis that thrombosis may play a significant role in this condition. Based on these findings, we systematically analysed the case histories of patients who developed CTEPH in order to test the hypothesis that splenectomy could be a risk factor for developing this severe pulmonary vascular condition.

\section{METHODS}

\section{Patients}

We retrospectively reviewed the charts of all 257 patients referred to our institution between 1989 and 1999 for CTEPH. The diagnosis of pulmonary hypertension was based on haemodynamic findings (mean pulmonary arterial pressure greater than $25 \mathrm{~mm} \mathrm{Hg}$ at rest or $30 \mathrm{~mm} \mathrm{Hg}$ at exercise, with a pulmonary artery wedge pressure below $12 \mathrm{~mm} \mathrm{Hg}$ ). Diagnosis of chronic thromboembolic disease was based on the presence of one or more mismatched segmental or larger perfusion defects in the ventilation-perfusion lung scan and on pulmonary angiography showing pouch defects, pulmonary artery webs or bands, intimal irregularities, abrupt angular narrowing of the major pulmonary arteries, and/or complete obstruction of main, lobar, or segmental vessels at their point of origin. ${ }^{13}$ Medical history, clinical characteristics, thrombotic risk factors, and haemodynamics of patients with CTEPH were described and analysed.

\section{Case-control study}

A case-control design was used to compare the prevalence of splenectomy in patients with CTEPH with that of patients with other chronic pulmonary diseases $(\mathrm{n}=180$; 53 pulmonary fibrosis, 41 emphysema, 30 diffuse bronchiectasis, 19 histiocytosis $\mathrm{X}$, and 37 miscellaneous end-stage pulmonary diseases) referred to our centre between 1989 and 1999 for lung transplantation and patients with idiopathic pulmonary arterial hypertension $(\mathrm{n}=276)$ evaluated during the same period.

\section{Statistical analysis}

Quantitative variables were presented as mean (SD) values and comparisons were made with the Student's $t$ test. The Abbreviations: CTEPH, chronic thromboembolic pulmonary
hypertension 
Table 1 Clinical and haemodynamic characteristics of patients who developed CTEPH after splenectomy

\begin{tabular}{|c|c|c|c|c|c|c|c|c|}
\hline Patient no & $\begin{array}{l}\text { Indication for } \\
\text { splenectomy }\end{array}$ & $\begin{array}{l}\text { Age at } \\
\text { splenectomy } \\
\text { (years) }\end{array}$ & $\begin{array}{l}\text { Interval between } \\
\text { splenectomy and } \\
\text { diagnosis of CTEPH } \\
\text { (years) }\end{array}$ & $\begin{array}{l}\text { History of } \\
\text { VTE }\end{array}$ & $\begin{array}{l}\text { Risk } \\
\text { factors }\end{array}$ & $\begin{array}{l}\text { Platelet count } \\
\text { at time of } \\
\text { diagnosis }\end{array}$ & $\begin{array}{l}\text { mPAP } \\
(\mathrm{mm} \mathrm{Hg})\end{array}$ & $\begin{array}{l}\mathrm{Cl} \\
\left(\mathrm{I} / \mathrm{mn} / \mathrm{m}^{2}\right)\end{array}$ \\
\hline 1 & Trauma & 32 & 3 & Yes & No & 414 & 60 & 2.76 \\
\hline 2 & Hodgkin's & 24 & 21 & No & No & 310 & 30 & 1.87 \\
\hline 3 & Gastric cancer & 41 & 6 & Yes & No & 162 & 27 & 2.63 \\
\hline 4 & Stomatocytosis & 31 & 17 & No & PS & 418 & 51 & 2.37 \\
\hline 5 & Spherocytosis & 2 & 35 & No & No & 179 & 48 & 1.80 \\
\hline 6 & Spherocytosis & 20 & 30 & No & NA & 200 & 63 & 2.90 \\
\hline 7 & AlHA & 54 & 14 & No & No & 360 & 30 & 3.07 \\
\hline 8 & Trauma & 33 & 20 & No & No & 285 & 47 & 2.07 \\
\hline 9 & Trauma & 32 & 24 & Yes & NA & 230 & 53 & 2.50 \\
\hline 10 & Trauma & 48 & 9 & No & No & 258 & 54 & 1.85 \\
\hline 11 & Trauma & 56 & 12 & Yes & NA & 289 & 32 & 2.77 \\
\hline 12 & Trauma & 26 & 25 & No & No & 211 & 57 & 2.80 \\
\hline 13 & Trauma & 52 & 11 & Yes & No & 208 & 47 & 1.90 \\
\hline 14 & Trauma & 21 & 21 & Yes & No & 336 & 53 & 3.41 \\
\hline 15 & Trauma & 39 & 2 & No & No & 295 & 33 & 4.20 \\
\hline 16 & Trauma & 21 & 30 & Yes & No & 188 & 42 & 2.50 \\
\hline 17 & Trauma & 46 & 19 & Yes & No & 448 & 61 & 3.83 \\
\hline 18 & Trauma & 53 & 10 & No & No & 239 & 67 & 1.64 \\
\hline 19 & Trauma & 40 & 10 & Yes & No & 197 & 40 & 2.54 \\
\hline 20 & Trauma & 20 & 12 & Yes & No & 300 & 47 & 2.24 \\
\hline 21 & Trauma & 21 & 9 & Yes & No & 355 & 49 & 1.60 \\
\hline 22 & Pancreatitis & 31 & 13 & Yes & No & 234 & 60 & 2.00 \\
\hline Mean (SD) & & $34(14)$ & $16(9)$ & & & $278(83)$ & $48.5(11.2)$ & $2.51(0.69)$ \\
\hline
\end{tabular}

AlHA, autoimmune haemolytic anaemia; $\mathrm{Cl}$, cardiac index; CTEPH, chronic thromboembolic pulmonary hypertension; mPAP, mean pulmonary arterial pressure; NA, not available; PS, protein S deficiency; VTE, acute venous thromboembolism.

prevalence of splenectomy was calculated for both groups and the $95 \%$ confidence intervals were determined. The $\chi^{2}$ test was used for statistical comparison. A p value of $<0.05$ was considered to indicate statistical significance.

\section{RESULTS}

\section{Case summaries}

Analysis of the 257 patients with CTEPH indicated that 22 had a history of splenectomy (14 men, mean (SD) age 48 (11) years). The indication for splenectomy, age at the time of splenectomy, interval between splenectomy and diagnosis of CETPH, and haemodynamics at the time of diagnosis are shown in table 1 . Twelve patients $(54.5 \%)$ had a known history of venous thromboembolism which occurred at least l year after splenectomy with no case of acute thromboembolic disease in the immediate postoperative period. The mean interval between splenectomy and diagnosis of CTEPH was 16 (9) years. All patients had clinically severe pulmonary hypertension, including 14 patients (64\%) in New York Heart Association functional class III or IV. Five patients (23\%) had experienced at least one episode of syncope.

Inherited thrombotic risk factor abnormalities (antithrombin, protein $\mathrm{C}$, protein $\mathrm{S}$ deficiencies and mutations of factor $\mathrm{V}$ and factor II) were determined in 19 of the 22 patients. Only one patient had a protein S deficiency (table 1). Antiphospholipid antibodies and lupus anticoagulant were not detected in the 18 patients tested (table 1), compared

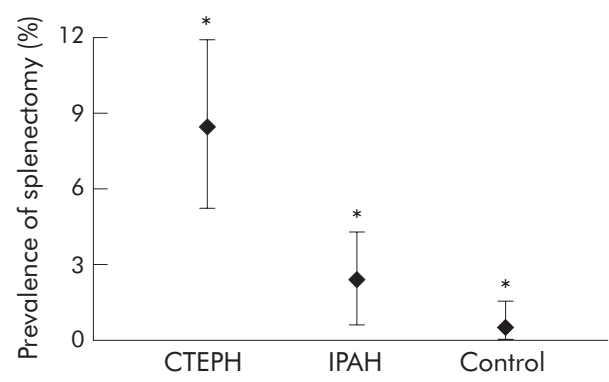

Figure 1 Prevalence of splenectomy in patients with chronic thromboembolic pulmonary hypertension (CTEPH), idiopathic pulmonary arterial hypertension (IPAH), and in those with other chronic pulmonary conditions (controls). Results are indicated as means and 95\% confidence interval (Cl). In patients with CTEPH, 8.6\% (95\% Cl 5.2 to 12.0) had a history of splenectomy compared with $2.5 \%(95 \% \mathrm{Cl} 0.7$ to 4.4$)$ and $0.56 \%(95 \% \mathrm{Cl} 0$ to 1.6$)$ in patients with IPAH and controls, respectively; ${ }^{*} p<0.01$ ( $\chi^{2}$ test).

with a prevalence of $20 \%$ in patients with CTEPH and no history of splenectomy. ${ }^{10}$ The total platelet count was within the normal range in all patients at the time of diagnosis of CTEPH.

All patients received medical treatment (warfarin, diuretics, and oxygen if needed). Eight eligible patients (36\%) underwent pulmonary thromboendarterectomy for proximal

Table 2 Basic demographic data of patients with CTEPH, IPAH and control subjects

\begin{tabular}{|c|c|c|c|}
\hline & $\begin{array}{l}\text { CTEPH } \\
(n=257)\end{array}$ & $\begin{array}{l}\text { IPAH } \\
(n=276)\end{array}$ & $\begin{array}{l}\text { Control } \\
(n=180)\end{array}$ \\
\hline $\begin{array}{l}\text { Sex ratio (F:M) } \\
\text { Mean (SD) age (years) } \\
\text { No }(\%) \text { of patients with splenectomy } \\
\text { (with } 95 \% \mathrm{Cl} \text { ) }\end{array}$ & $\begin{array}{l}0.9: 1 \\
51(14)^{*} \\
22(8.6 \%)^{*} \\
(5.2 \text { to } 12)\end{array}$ & $\begin{array}{l}1.5: 1 \dagger \\
46(15) \\
7(2.5 \%) \\
(0.7 \text { to } 4.4)\end{array}$ & $\begin{array}{l}0.8: 1 \\
47(9) \\
1(0.6 \%) \\
(0.0 \text { to } 1.6)\end{array}$ \\
\hline \multicolumn{4}{|c|}{$\begin{array}{l}\text { CTEPH, chronic thromboembolic pulmonary hypertension; IPAH, idiopathic pulmonary arterial hypertension; } \mathrm{Cl} \text {, } \\
\text { confidence interval. } \\
\text { * } \mathrm{p}<0.01 \text { IPAH } v \text { control groups ( } \chi^{2} \text { or unpaired Student's } t \text { tests, as appropriate). } \\
t p<0.05 \mathrm{CTEPH} v \text { control groups ( } \chi^{2} \text { test). }\end{array}$} \\
\hline
\end{tabular}


CTEPH. This proportion of operable patients was similar in non-splenectomised patients with CTEPH reported in the literature $(37 \%)$. Surgery was successful in seven patients and one patient died of refractory right ventricular failure after surgery. Of the 14 remaining patients, three were treated with continuous epoprostenol infusion for distal obstruction and two have undergone lung transplantation. Examination of the explanted lung tissue of these two patients revealed multiple thrombotic lesions of the pulmonary vasculature, characterised by intimal fibrosis associated with organised thrombi and recanalisation of small pulmonary arteries.

\section{Case-control study}

A case-control study was performed to compare the prevalence of splenectomy in patients with CTEPH $(\mathrm{n}=257)$ with that of patients with idiopathic pulmonary arterial hypertension $(\mathrm{n}=276)$ and other pulmonary diseases $(n=180)$ referred to our centre for lung transplant evaluation. Basic data are shown in table 2.

In patients with CTEPH, 8.6\% (95\% CI 5.2 to 12.0 ) had a history of splenectomy compared with $2.5 \%$ (95\% CI 0.7 to 4.4 ) and $0.56 \%$ (95\% CI 0 to 1.6 ) in cases of idiopathic pulmonary arterial hypertension and other chronic pulmonary conditions, respectively ( $\mathrm{p}<0.01, \chi^{2}$ test; fig 1$)$.

\section{DISCUSSION}

Five thousands splenectomies are performed every year in France. ${ }^{14}$ It can therefore be estimated that the prevalence of splenectomy in a general population with a mean age of 50 years would be around $0.4 \%$, similar to that observed in patients referred for chronic pulmonary diseases in our lung transplantation unit $(0.5 \%)$. Thus, the $8.6 \%$ frequency of splenectomy in CTEPH is 20 times greater than expected in the general population. This finding supports the concept that splenectomy may promote recurrent thromboembolic disease and/or in situ thrombosis and could be a risk factor for CTEPH. Indeed, in recent years it has become clear that embolism may not be a prerequisite for thromboembolic pulmonary hypertension and CTEPH may be a consequence of thrombosis rather than embolism. In subjects displaying idiopathic pulmonary arterial hypertension, a history of splenectomy was found in $2.5 \%$. This is higher than in the general population but markedly less than the $11.5 \%$ frequency reported by Hoeper et al. ${ }^{12}$ However, this apparent discrepancy may in fact reflect the continuum between proximal CTEPH which will benefit from pulmonary endarterectomy, distal cases which should not be proposed for pulmonary endarterectomy, and thrombotic forms of idiopathic pulmonary arterial hypertension. Interestingly, only $36 \%$ of splenectomised patients with CTEPH in our series had a thromboendarterectomy, highlighting the fact that most cases were distal (or had a contraindication due to significant co-morbidities). Moreover, pulmonary hypertension described in splenectomised subjects by Hoeper et al had prominent thrombotic pulmonary arteriopathy and, in one patient, these lesions recurred after lung transplantation. These findings tend to indicate a role of splenectomy in the development of a prothrombotic state in these individuals. The patients described in the present report developed CTEPH 7-25 years after splenectomy. In four of the 22 cases the indication for splenectomy was chronic haemolysis (table 1). Chronic haemolysis per se is not a cause of thrombosis but, when splenectomised, these patients appear to have an increased propensity for thrombosis. ${ }^{15-26}$ Steward et al ${ }^{17}$ reported a series of 18 patients (nine with a history of splenectomy) with inherited stomatocytosis followed for more than 20 years. All splenectomised subjects with inherited stomatocytosis developed at least one documented thromboembolic episode 2-26 years after splenectomy, leading in four cases to CTEPH. We have recently reported a similar case of distal CTEPH treated by heart-lung transplantation after bridge therapy with intravenous epoprostenol (patient no 4 in table 1). ${ }^{18}$ In non-splenectomised subjects no thromboembolic event has been reported.${ }^{17}$ It is believed that splenectomy in patients with chronic haemolysis may predispose to thromboembolic disease that might eventually lead to CTEPH. Hayag-Barin et al ${ }^{19}$ described the case of a 30 year old man with hereditary spherocytosis who presented 29 years after splenectomy with recurrent pulmonary emboli resulting in severe pulmonary hypertension. In addition, Chou et $a l^{20}$ reported a case of recurrent thromboembolic disease and chronic pulmonary hypertension in an adult patient with pyruvate kinase deficiency who underwent splenectomy as a child. Other vascular and thrombotic phenomena that have been described in patients following splenectomy for hereditary haemolytic anaemia include priapism, arterial thrombosis, portal vein thrombosis, and superior mesenteric vein thrombosis. ${ }^{17} 21$

In patients with hereditary and chronic haemolytic anaemia necroscopic findings have shown an increased frequency $(44 \%)$ of obstructive pulmonary arterial lesions in splenectomised patients with $\beta$-thalassaemia. ${ }^{22}$ One of the mechanisms involved would be a prothrombotic state due to higher thrombin formation in splenectomised patients. Abnormal erythrocytes would be paramount for the activation of mechanisms for thrombin synthesis.

It is noteworthy that most patients reported in the present study had no haematological condition and splenectomy was indicated after trauma in 15 of the 22 cases. Interestingly, only eight of these 15 patients (53\%) had a history of documented venous thromboembolism which occurred in all cases at least 1 year after splenectomy and never immediately after the surgery. Moreover, the work-up for acquired or inherited thrombotic risk factors was negative for all of them with the exception of a single case of protein S deficiency. This finding is consistent with the published evidence that splenectomy is a risk factor for thromboembolic disease even in the absence of an underlying haematological condition. Coltheart et al reported a $10.7 \%$ frequency of pulmonary thromboembolic disease in a retrospective study of 150 consecutive splenectomies performed over a 5 year period. ${ }^{23}$ Likewise, a review of 37012 necropsies performed over 20 years analysed 202 deceased adults who had a history of splenectomy. The number of thromboembolic complications related to death in these patients was compared with that of a matched deceased population who had not undergone splenectomy $(\mathrm{n}=403)$. This study showed that pulmonary embolism was the major or a contributory cause of death more often in the splenectomy group than in the control group (35.6\% $\vee 9.7 \%, \mathrm{p}<0.001)$, supporting the hypothesis that splenectomy might be a risk factor for pulmonary thromboembolic disease. ${ }^{24}$

In our series only 12 of the 22 splenectomised patients with CTEPH had a known history of venous thromboembolic disease. This is consistent with recent studies indicating that symptom-free venous thromboembolic disease is common and that symptomatic pulmonary embolism is often overlooked or misdiagnosed. ${ }^{25-27}$

There is some speculation as to the possible role of splenectomy in promoting venous thromboembolic disease. While transient thrombocytosis is expected immediately after splenectomy, it is not usually associated with thrombotic events. ${ }^{28}{ }^{29}$ In addition, our patients developed CTEPH several years after splenectomy when thrombocytosis was no longer present (table 1). A role for components of the erythrocyte membrane has been proposed in venous thromboembolic disease occurring after splenectomy. ${ }^{30}{ }^{31}$ Indeed, the anionic 
phospholipids of the erythrocyte membrane, including the phosphatidylserine known to facilitate the coagulation process, are localised in the inner membrane leaflet of the cell membrane in normal individuals. ${ }^{31}$ Abnormal exposure of phosphatidylserine at the outer leaflet of erythrocyte membrane would promote an activation of the coagulation process by fixation of enzymatic complexes. Kuypers et al ${ }^{30}$ showed that the number of erythrocytes with modified phosphatidylserine expression was 20 times higher after splenectomy in thalassaemic patients. These cells also acquired a procoagulant phenotype as a marker of accelerated thrombin formation. The loss of the filtering function of the spleen would allow abnormal red cells to remain in the peripheral circulation after splenectomy, resulting in the activation of the coagulation cascade even in the absence of chronic haemolysis.

Our study has some limitations. Firstly, we used a retrospective design and studied three groups in which patients were not matched for age and sex. Secondly, trauma was the main indication for splenectomy and abdominal surgery following this trauma could be an associated factor for thromboembolic disease even if no patients had developed a documented thromboembolic disease immediately after the surgery.

Ideally, to address the relationship between splenectomy and CTEPH, a group of patients with splenectomy and no other thromboembolic risk factors should be matched with a group of patients with intact spleens and then be followed up to examine the prevalence of CTEPH. Unfortunately, our database did not allow us to perform such an analysis. However, on the basis of our present findings and after careful analysis of the published medical literature, we conclude that splenectomy might be a risk factor for venous thromboembolic disease and subsequent CTEPH.

Based on these findings, it may be relevant to discuss anticoagulation prophylaxis following splenectomy in situations where there is a risk of thromboembolic disease such as surgery, immobilisation, and for patients in plaster. There is, however, a lack of evidence in the literature to support the systematic use of oral anticoagulation in this group of patients.

\section{Authors' affiliations}

X Jaïs, V loos, C Jardim, O Sitbon, F Parent, A Hamid, G Simonneau, M Humbert, UPRES EA 2705, Centre des Maladies Vasculaires Pulmonaires, Service de Pneumologie et Réanimation Respiratoire, Hôpital Antoine Béclère, Assistance Publique-Hôpitaux de Paris, Université Paris Sud, Clamart, France

E Fadel, P Dartevelle, UPRES EA 2705, Service de Chirurgie Thoracique, Vasculaire et de Transplantation Pulmonaire, Centre Chirurgical Marie Lannelongue, Université Paris Sud, Le Plessis Robinson, France

This study was supported by grants from Université Paris-Sud and Legs Poix.

Competing interests: none declared.

\section{REFERENCES}

1 Fedullo PF, Auger WR, Kerr KM, et al. Chronic thromboembolic pulmonary hypertension. N Engl J Med 2002;345:1465-72.
2 Gillum RF. Pulmonary embolism and thrombophlebitis in the United States 1975-1985. Am Heart J 1987; 1 14:1262-4.

3 Lilienfield DE, Chan E, Ehland J. Mortality from pulmonary embolism in the United States: 1962-1984. Chest 1990:98:1067-72.

4 Olman MA, Marsh JJ, Lang IM, et al. Endogenous fibrinolytic system in chronic large vessel thromboembolic pulmonary hypertension. Circulation 1992;86:1241-8.

5 Lang IM, Marsh JJ, Olman MA, et al. Parallel analysis of tissue-type plasminogen activator and type I plasminogen activator inhibitor in plasma and endothelial cells derived from patients with chronic pulmonary thromboemboli. Circulation 1994;90:706-12.

6 Lang IM, Marsh JJ, Olman MA, et al. Expression of type I plasminogen activator inhibitor in chronic pulmonary thromboemboli. Circulation 1994;89:2715-21.

7 Moser KM, Auger WR, Fedullo PF. Chronic major vessel thromboembolic pulmonary hypertension. Circulation 1990;81:1735-43.

8 Lang IM, Klepetho W, Pabinger I. No increased prevalence of the factor V Leiden mutation in chronic major vessel thromboembolic pulmonary hypertension. Thromb Haemost 1996;76:476-7.

9 Moser KM, Bloor CM. Pulmonary vascular lesions occurring in patients with chronic major vessel thromboembolic pulmonary hypertension. Chest 1993; 103:685-92.

10 Wolf $M$, Boyer-Neumann $C$, Parent $F$, et al. Thrombotic risk factors in pulmonary hypertension. Eur Respir J 2000;15:395-9.

11 Auger WR, Permpikul P, Moser KM. Lupus anticoagulant, heparin use and thrombocytopenia in patients with chronic thromboembolic pulmonary hypertension. A preliminary report. Am J Med 1995;99:392-6.

12 Hoeper MM, Niedermeyer J, Hoffmeyer F, et al. Pulmonary hypertension after splenectomy? Ann Intern Med 1999;130:506-9.

13 Moser KM, Auger WR, Fedullo PF. Chronic major-vessel thromboembolic pulmonary hypertension. Circulation 1990:81:1735-43.

14 Beytout J, Tournilhac O, Laurichesse $\mathrm{H}$. Management of splenectomized patients. Presse Med 2003;32:S3.

15 Hirsh J, Dacie JV. Persistent post-splenectomy thrombocytosis and thromboembolism. Br J Haematol 1966;12:44-53.

16 Hirsh J, McBride JA, Dacie JV. Thromboembolism and increased platelet adhesiveness in post-splenectomy thrombocytosis. Aust Ann Med 1966;15:122-8.

17 Steward GW, Amess JAL, Eber SW, et al. Thrombo-embolic disease after splenectomy for hereditary stomatocytosis. Br J Haematol 1996:93:303-10.

18 Jaiis X, Till S J, Cynober T, et al. An extreme consequence of splenectomy in dehydrated hereditary stomatocytosis: gradual thromboembolic pulmonary hypertension and lung-heart transplantation. Hemoglobin 2003;27:139-47.

19 Hayag-Barin JE, Smith RE, Tucker Jr FC. Hereditary spherocytosis, thrombocytosis, and chronic pulmonary emboli: a case report and review of the literature. Am J Hematol 1998;57:82-4.

20 Chou R, DeLoughery TG. Recurrent thromboembolic disease following splenectomy for pyruvate kinase deficiency. Am J Hematol 2001;67:197-9.

21 Bertolotti M, Loria P, Martella P, et al. Bleeding jejunal varices and portal thrombosis in a splenectomized patient with hereditary spherocytosis. Dig Dis Sci 2000:45:373-7.

22 Sonakul D, Pacharee P, Laohapand T, et al. Pulmonary artery obstruction in thalassemia. Southeast Asian J Trop Med Public Health 1980;1 1:416-23.

23 Coltheart G, Little JM. Splenectomy: a review of morbidity. Aust NZ J Surg 1976:46:32-6.

24 Pimpl W, Dapunt $\mathrm{O}$, Kaindl $\mathrm{H}$, et al. Incidence of septic and thromboembolicrelated deaths after splenectomy in adults. Br J Surg 1989;76:517-21.

25 Meignan M, Rosso J, Gauthier H. Systematic lung scans reveal a high frequency of silent pulmonary embolism in patients with proximal deep venous thrombosis. Arch Intern Med 2000;160:159-64.

26 Ryu JH, Olson EJ, Pellikka PA. Clinical recognition of pulmonary embolism: problem of unrecognized and asymptomatic cases. Mayo Clin Proc 1998;73:873-9.

27 Dartevelle $\mathbf{P}$, Fadel E, Mussot S, et al. Chronic thromboembolic pulmonary hypertension. Eur Respir J 2004;23:637-48

28 Boxer MA, Braun J, Ellman L. Thromboembolic risk of postsplenectomy thrombocytosis. Arch Surg 1978;113:808-9.

29 Visudhiphan S, Ketsa-Ard K, Piankijagun A, et al. Blood coagulation and platelet profiles in persistent post splenectomy thrombocytosis. The relationship to thromboembolism. Biomed Pharmacother 1985;39:264-71.

30 Kuypers FA, Yuan J, Lewis RA, Snyder LM, et al. Membrane phospholipid asymmetry in human thalassemia. Blood 1998;91:3044-51.

31 Atichartakarn V, Angchaisuksiri P, Aryurachai K, et al. Relationship between hypercoagulable state and erythrocyte phosphatidylserine exposure in splenectomized haemoglobin $\mathrm{E} / \beta$-thalassemic patients. $\mathrm{Br} J$ Haematol 2002;118:893-8. 